\title{
MONTE CARLO ANALYSIS OF AN NE213 DETECTOR
}

S. N. Cramer

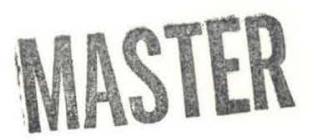




\section{DISCLAIMER}

This report was prepared as an account of work sponsored by an agency of the United States Government. Neither the United States Government nor any agency Thereof, nor any of their employees, makes any warranty, express or implied, or assumes any legal liability or responsibility for the accuracy, completeness, or usefulness of any information, apparatus, product, or process disclosed, or represents that its use would not infringe privately owned rights. Reference herein to any specific commercial product, process, or service by trade name, trademark, manufacturer, or otherwise does not necessarily constitute or imply its endorsement, recommendation, or favoring by the United States Government or any agency thereof. The views and opinions of authors expressed herein do not necessarily state or reflect those of the United States Government or any agency thereof. 


\section{DISCLAIMER}

Portions of this document may be illegible in electronic image products. Images are produced from the best available original document. 
This report was prepared as an account of work sponsored by the United States Government. Neither the United States nor the United States Atomic Energy Commission, nor any of their employees, nor any of their contractors, subcontractors, or their employees, makes any warranty, express or implied, or assumes any legal liability or responsibility for the accuracy, completeness or usefulness of any information, apparatus, product or process disclosed, or represents that its use would not infringe privately owned rights. 
ORNL-TM-4149

Contract No. W-7405-eng-26

MATHEMATICS DIVISION

MONTE CARLO ANALYSIS OF AN NE213 DETECTOR

S. N. Cramer

MARCH 1973

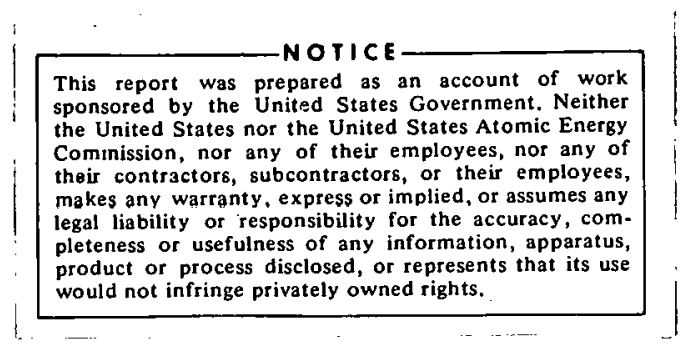

NOTICE This document contains information of a preliminary nature and was prepared primarily for internal use at the Oak Ridge National Laboratory. It is subject to revision or correction and therefore does not represent a final report.

OAK RIDGE NATIONAL LABORATORY

Oak Ridge, Tennessee 37830

operated by

UNION CARBIDE CORPORATION

for the

U.S. ATOMIC ENERGY COMMISSION 


\section{THIS PAGE}

WAS INTENTIONALLY

LEFT BLANK 
CONTENITS

Page

Abstract .................... 1

I. Introduction .................... 1

II. Physical Considerations . . . . . . . . . . . I

III. System Description............... . . . 3

IV. Data and Code Changes . . . . . . . . . . . 3

V. Spectra Calculations . . . . . . . . . . . 4

References ............... 14 
1. Proton Spectrum for the $15 \mathrm{MeV}$ Source . . . . . . 5

2. Proton Spectrum for the $3.05 \mathrm{MeV}$ Source . . . . . . 6

3. Alpha Particle Spectrum for the $15 \mathrm{MeV}$ Source . . . . 7

4. Proton Spectrum for a $14 \mathrm{MeV}$ Source with no Collisions with Carbon and no Multiple Collisions Allowed . . . . 8

5. Proton Spectrum for a $14 \mathrm{MeV}$ Source with no Collisions with Carbon Allowed ............... 10

6. Alpha Particle Spectra for a $14 \mathrm{MeV}$ Source with no Q Values Included in the Calculation . . . . . . . 12 


\section{ABSTRACT}

A Monte Carlo analysis of an $\mathrm{NE} 213$ detector has been performed using the ESP code. "The investigation involved" calculation of the alpha particle and proton spectra pro- : . duced in the detector from neutron reactions with hydrogen and carbon. The sensitivity of these calculated spectra has been determined with respect to first collision only, hydrogen scatter only, and reaction $Q$ value.

\section{INTRODUCTION}

A Monte Carlo analysis of a nominal $2 \times 2$ inch cylindrical NE213 detector has been performed using the $\mathrm{ESP}^{l}$ code. The investigation involved calculation of the alpha particle spectrum due to the $\left(n, n^{\prime}\right) 3 \alpha$ and the $(n, \alpha)$ reactions with carbon and the proton spectrum due to. neutron collisions with hydrogen. The spectra are integrated over the volume of the detector. The neutron scurce consisted of a monoenergic beam of neutrons incident on one end of the detector. The energy of the secondary particles was determined from an energy balance following each collision.

\section{PHYSICAL CONSIDERATIONS}

The purpose of this study was to determine the total energy of alpha particles and of protons produced per incident neutron over the entire vclume of the detector so that pulse height spectra could be estimated using the light curve for the detector. In the calculation it was assumed that each neutron could produce no more than one secondary particle and that the energy of each particle produced was the sum of the energies of all particles of that type actually produced 
by that neutron. That is, a neutron having two collisions with hydrogen produced only one proton with an energy equal to the sum of the two, had they been produced separately. Likewise, only one alpha particle was produced from a $\left(n, n^{\prime}\right) 3 \alpha$ reaction with carbon with an energy equal to the sum of the three individual alpha particle energies. In reality the detection equipment cannot distinguish between these individual particles of the same type, and it appears that only one higher energy particle has been detected. However, these assumptions assume a linear light output. Also, these alpha particles and protons give up their energy by ionization quickly in close vicinity of the reaction which produced them. In the calculation it has been assumed that this energy deposition takes place at the collision site, and there is no tracking of the charged particles. The energy contribution, in the laboratory system, to the alpha particle produced per neutron for each neutron-carbon collision is $\mathrm{E}_{\alpha^{\prime}}$, where:

$$
E_{\alpha}=E_{n}^{i}-E_{n}-|Q|
$$

and $E_{n}^{\prime}=$ incident neutron energy,

$$
\begin{aligned}
& E_{n}=\text { exit neutron energy }\left(E_{n}=0 \text { for the }(n, \alpha)\right. \text { reaction), } \\
& Q=\text { reaction } Q \text { value }\left\{\begin{array}{l}
Q=-7.27 \mathrm{MeV} \text { for }\left(n, n^{\prime}\right) 3 \alpha \\
Q=-5.695 \mathrm{MeV} \text { for }(n, \alpha)
\end{array}\right.
\end{aligned}
$$

Although the correct energy of each alpha particle should be determined from multiple body collision mechanics, the above equation should suffice for the present purposes. The recoil proton energy is determined from a similar relationship with $Q=0$. 


\section{SYSTEM DESCRIPTION}

The detector investigated: was an $1 \mathrm{NE} 213$ detector-2 inches in height and 2 inches in diameter. The carbon and hydrogen densities were 0.04023 atoms/barn-cm and 0.04871 atoms/barn-cm, respectively. The : source was a monoenergic beam of neutrons incident on and perpendicular to one base of the cylinder. Source energies used were 15 and $3.05 \mathrm{MeV}$.

\section{DATA AND CODF CHANGFS}

The data used in the calculation was ENDF/B material number 1165 for carbon and 1148 for hydrogen. However, in the 1165 data the $\left(n, n^{\prime}\right) 3 \alpha$ reaction $(M T=23)$ has been combined with the continuum inelastic scattering. In order to investigate the ( $\left.n, n^{\prime}\right) 3 \alpha$ reaction explicitely, the MT $=23$ and $M T=91$ (inelastic continuum) data from the version II ENDF/B data, MAT = 1140, was combined with the 1165 data.

The standard ESP code utilizes nonabsorption scattering; that is, all collisions are scattering collisions and the computational neutron weight is multiplied by $\Sigma_{S} / \Sigma_{T}$, the nonabsorption probability for the medium. In order to produce secondary particles and determine their energies, the code was modified to do analog scattering. At each collision if a random number $R \leq \Sigma_{S} / \Sigma_{T}(0 \leq R \leq 1)$, the neutron is scattered and the calculational weight remains unity; otherwise, the neutron is absorbed and the history is terminated. In this manner the secondary particle energy can be accurately determined from the energy loss of the scattered neutron. Also, since the $(n, \alpha)$ reaction with carbon represents the only appreciable absorption in the system, an alpha particle is produced when a neutron is absorbed. 


\section{SPECTRA CALCULATIONS}

The proton spectra for the $15 \mathrm{MeV}$ and $3.05 \mathrm{MeV}$ source energies are given in Figs. 1 and 2, respectively. Figure 3 gives the alpha particle spectrum for the $15 \mathrm{MeV}$ source. There is no alpha particle spectrum for the $3.05 \mathrm{MeV}$ source since this energy is below the threshold values for $\left(n, n^{\prime}\right) 3 \alpha$ and $(n, \alpha)$ reactions. The remaining curves will be used to explain the calculated spectra based on the calculational model. A $14 \mathrm{MeV}$ source is used in these calculations. The error bars on all histograms represent one standard deviation of the mean.

Figure 4 shows a calculation resulting from first collisions with hydrogen. No carbon collisions are allowed and the neutron history is terminated following one collision with hydrogen. This curve can be determined analytically from

$$
E=\frac{E^{\prime}}{(A+1)^{2}}\left(A^{2}+2 \eta A+I\right)
$$

where $E$ = neutron energy after collision (lab),

$E^{\prime}=$ neutron energy before collision (lab),

$\eta=\mathrm{cm}$ scattering angle cosine,

$A=$ mass ration.

For hydrogen, $\eta$ is also the lab scattering angle cosine and the equation reduces to

$$
E=\frac{E^{\prime}}{2}(\eta+1)
$$




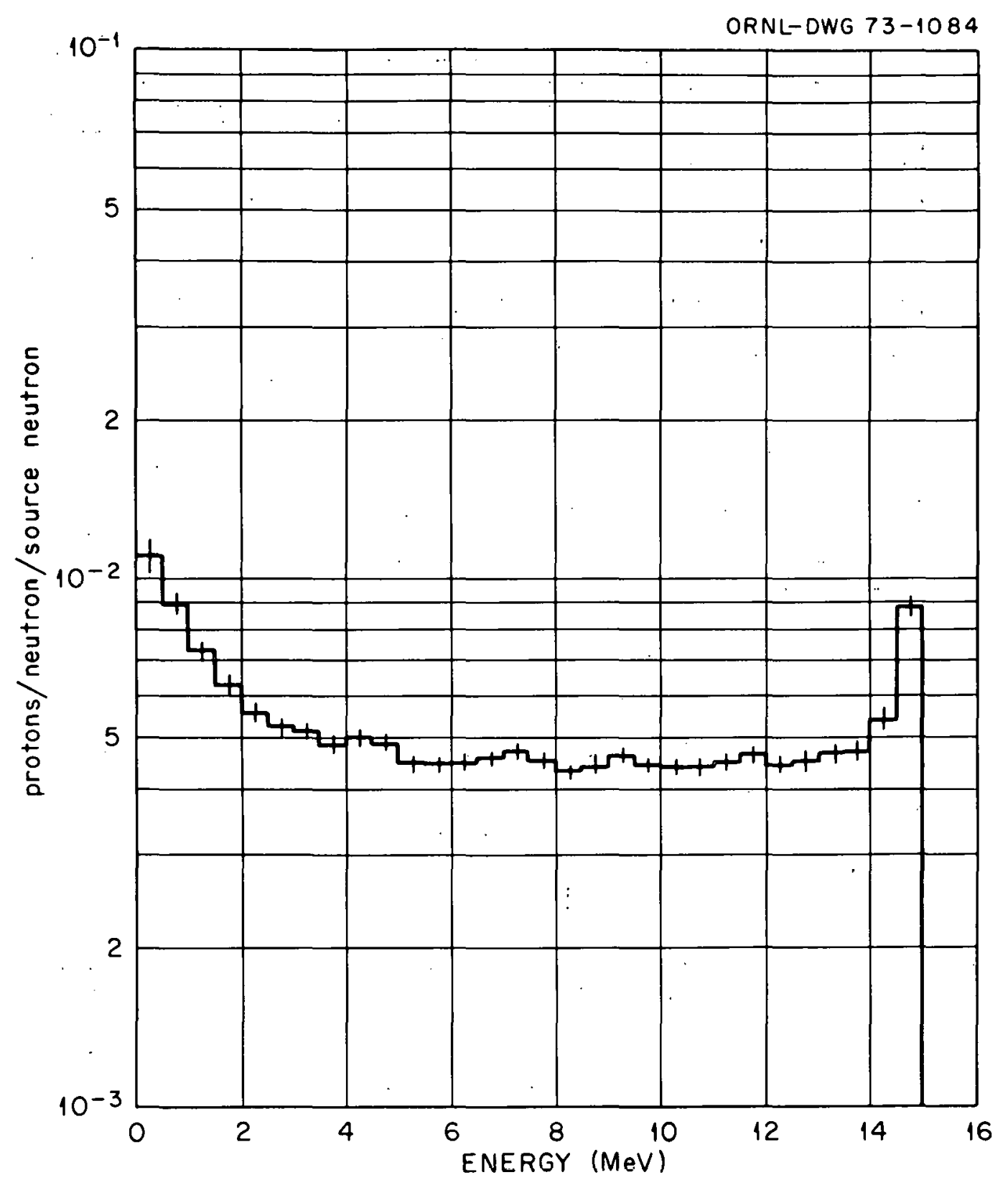

Fig. 1. Proton Spectrum for the $15 \mathrm{MeV}$ Source. 




Fig. 2. Proton Spectrum for the $3.05 \mathrm{MeV}$ Source. 


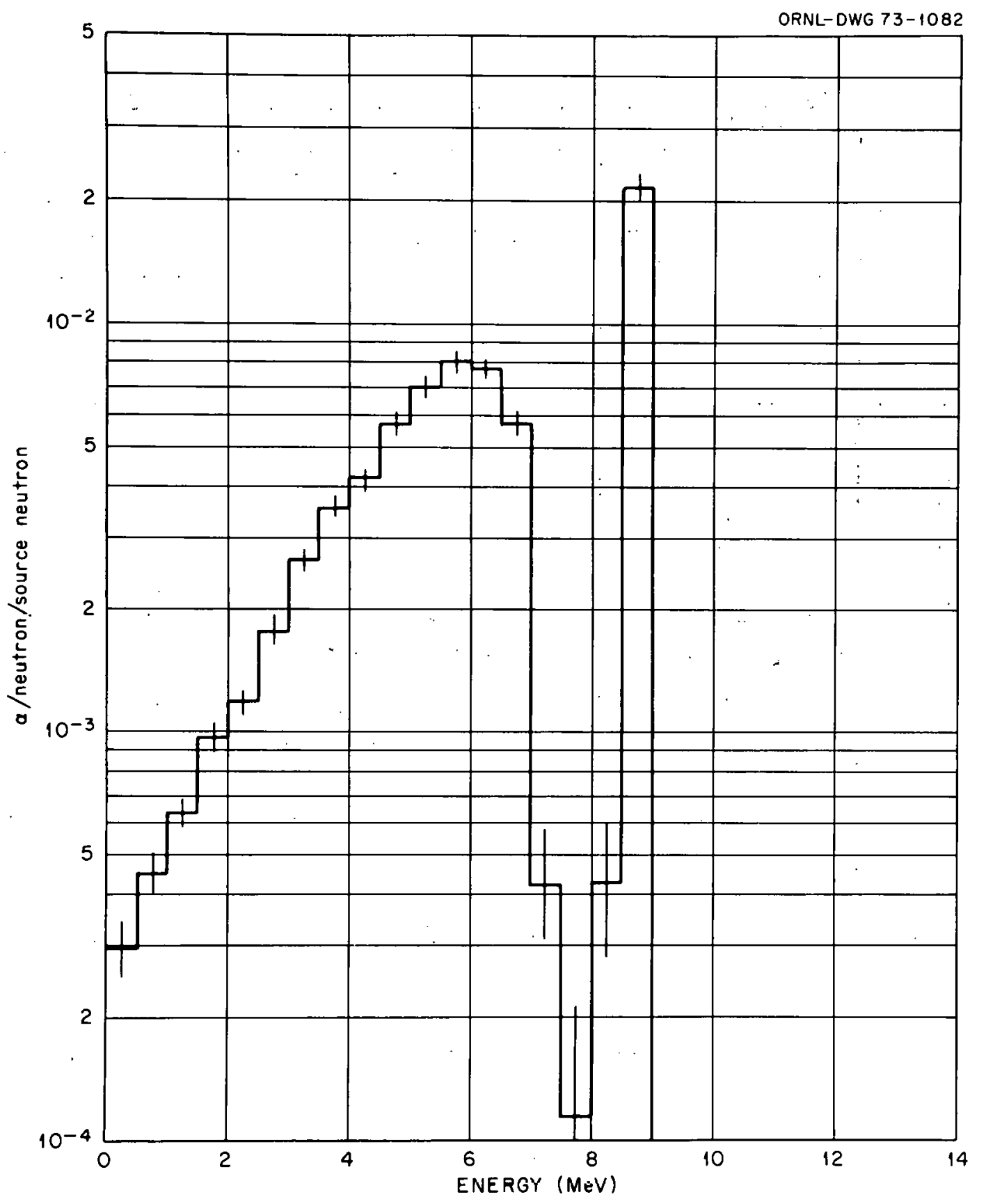

Fig. 3. Alpha Particle Spectrum for the $15 \mathrm{MeV}$ Source. 


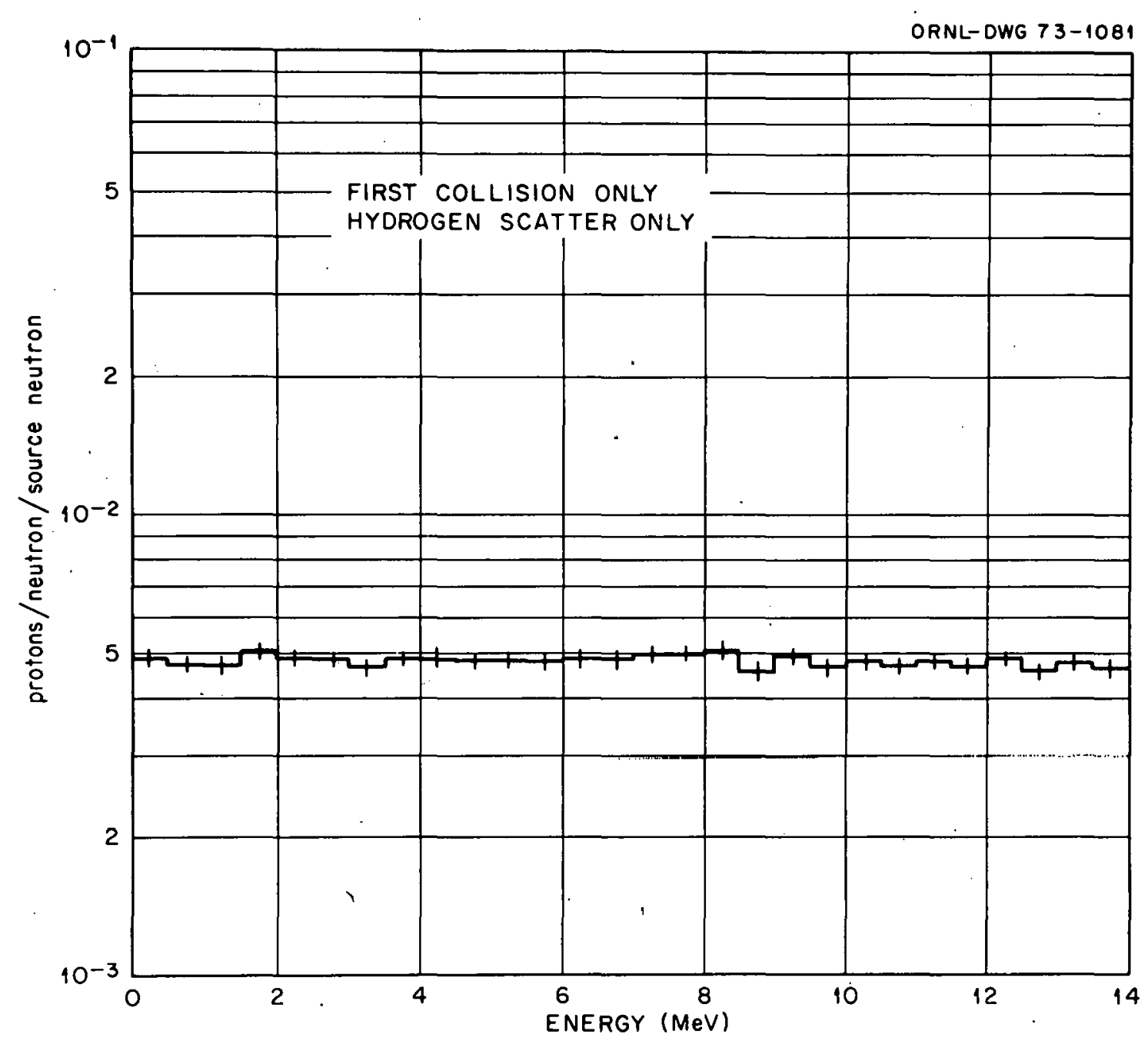

Fig. 4. Proton Spectrum for a $14 \mathrm{MeV}$ Source with no Collisions with Carbon and no Multiple Collisions Allowed. 
For isotropic scattering, $\eta$ is picked uniformly between \pm 1 , and the final neutron energy is uniformly distributed between 0 and $E^{\prime}$. Thus, the recoil proton energy is also uniformly distributed from 0 to $E^{\prime}, *$ and the broad flat area of the spectra in Figs. 1 and 2 is due to single scattering with hydrogen.

Figure 5 shows proton spectrum calculated from hydrogen scattering only, but with multiple collisions allowed. The spike at the source energy is due to this multiple scattering effect. Recall that the calculational model allowed a maximum of only one proton produced per. neutron and all hydrogen scattering energy loss for each neutron was combined into the energy of the single proton produced. In addition then to the flat spectrum in Fig. 4, additional hydrogen scatters tend to increase the energy of the one proton produced. The high energy portion of the spectrum in Fig. 5 results from collision sequences in which the neutron energy is decreased close to zero, all the energy going to the high energy proton. The low energy portion of the spectrum results from neutrons having only one small angle (and small energy loss) scatter with hydrogen at the source energy and escaping the system with no further collisions, producing a low energy

*The isotropic scattering for hydrogen had to be programmed directly into the code. Use of the standard Coveyou scattering technique2 and the ENDF/B data for 1148 permitted scattering in discrete directions only, making the energy loss discrete, also. This effect would disappear if there were any significant multiple scatterings or if the source was a continuous spectrum over a wide energy range. 




Fig. 5. Proton Spectrum for a $14 \mathrm{MeV}$ Source with no Collisions with Carbon Allowed. 
proton. This multiple collision effect with hydrogen is evident at high energies in Figs. 1 and 2. Since Fig. 2 is similar in shape to Fig. 5, it is apparent that the low energy spectrum in Fig. 1 is due to carbon scattering since the source for Fig. 2 is below the carbon reaction thresholds. First collisions with carbon produce a low energy neutron spectrum and subsequent neutron-hydrogen collisions produce lower energy recoil protons, which would add to the low energy spectrum of Fig. 5 if carbon collisions had been allowed.

Figure 6 shows an alpha particle spectrum calculated with the $Q$ value equal to zero in Eq. (1). That is, all neutron energy loss from the $\left(n, n^{\prime}\right) 3 \alpha$ and $(n, \alpha)$ reactions with carbon was converted into alpha particle energy. Hydrogen scatter and multiple scattering were allowed in this calculation. The $(n, \alpha)$ reaction gives a large contribution to the alpha particle spectrum at the source since the neutron is abscrbed and the entire energy loss goes into the alpha particle energy. The $(n, \alpha)$ reaction contribution after a scatter has occurred is reduced due to lower neutron energy at absorption. The $\left(n, n^{\prime}\right) 3 \alpha$ reaction contribution to the spectrum in Fig. 6 reflects the evaporation model used in calculating the secondary neutron energy from the ( $\left.n, n^{\prime}\right)$ reaction. The neutron energy loss, and alpha particle energy gain, covers almost the entire spectrum. By inserting the appropriate $Q$ values into the calculation, Fig. 3 is produced. That is, the $(n, \alpha)$ contribution is reduced by its $Q$ value from that shown in Fig. 6 to that in Fig. 3. Likewise, the $\left(n, n^{\prime}\right) 3 \alpha$ contribution to the alpha particle spectrum is 


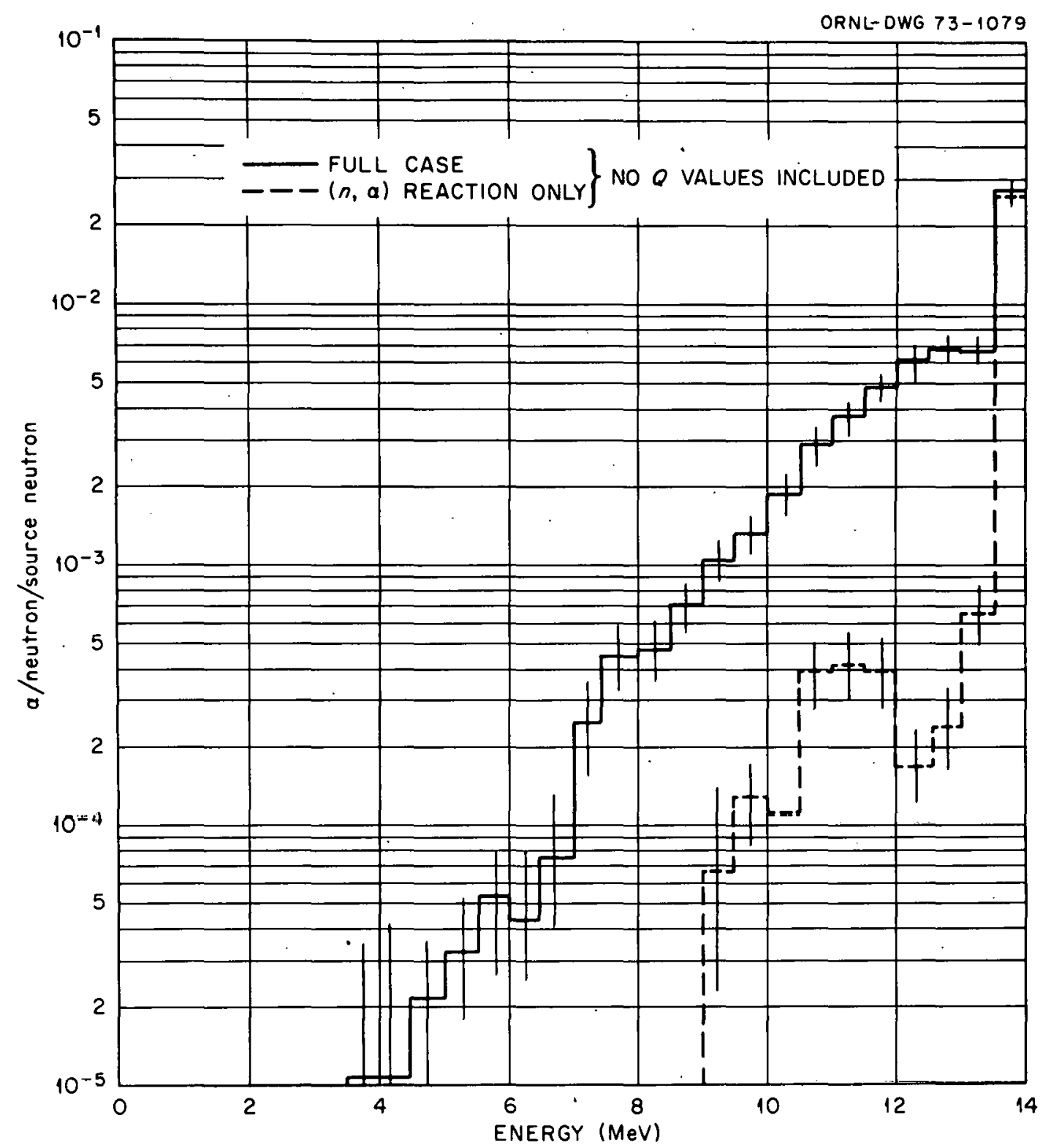

Fig. 6. Alpha Particle Spectra for a $14 \mathrm{MeV}$ Source with no Q Values Included in the Calculation. 
reduced by its $Q$ value from Fig. 6 to that in Fig. 3, and the two reaction contributions are separated in Fig. 3 relative to that in Fig. 6 due to the greater magnitude of the $\left(n, n^{\prime}\right) 3 \alpha$ Q value. 
REFERENCES

1. S. N... Cramer, R. S. Carlsmith, G. W. Morrison, G. W. Perry, and J. L. Lucius, "ESP - A General Monte Carlo Reactor Analysis Code," ORNL-TM-3164 (1972) .

2. D. C. Irving, R. M. Freestone, Jr., and F. B. K. Kam, "05R, A General-Purpose Monte Carlo Neutron Transport Code," ORNL-3622 (1965). 
INTERNAL DISTRIBUTION

1. T. W. Armstrong

2. D. E. Bartine

3. A. A. Brooks

4. H. P. Carter

5. R. L. Childs

6. C. E. Clifford

7-16. S. N. Cramer

17. J. K. Dickens

18. W. W. Engle, Jr.

19. G. F. Flanagan

20. W. E. Ford, III

21. R. M. Freestone, Jr.

22. T. A. Gabriel

23. N. M. Greene

24. T. J. Hoffman

25. W. H. Jordan

26. T. D. Jones

27. W. E. Kinne'y

28. J. R. Knight

29. J. Lewin

30. T. A. Love

31. J. L. Lucius

32. R. E. Maerker

33. F. C. Maienschein

34. B. J. McGregor

35. G. L. Morgan

36. G. W. Morrison
37. F. J. Muckenthaler

38. F. R. Mynatt

39. E. M. Oblow

40. J. V. Pace

41. R. W. Peelle

42. S. K. Penny

43. F. G. Perey

44. L. M. Petrie

45. W. A. Rhoades

46. R. W. Roussin

47. A. H. Snell

48. P. N. Stevens

49. J. G. Sullivan

50. J. H. Thorngate

51. D. K. Trubey

52. J. E. White

53. G. E. Whitesides

54. R. Q. Wright

55. A. Zucker

56-57. Central Research Library ORNL Y-12 Technical Library

58. Document Reference Section

59-63. Laboratory Records

64. Laboratory Records ORNL RC

65-74. Math. Division Library

75. ORNL Patent Office

\section{EXTERILI DISTRIBUTION}

76. W. H. Hannum, Division of Reactor Development and Technology, U. S. Atomic Energy Commission, Washington, D. C. 20545

77. P. B. Hemmig, Division of Reactor Development and Technclogy, U. S. Atomic Energy Commission, Washington, D. C. 20545

78. Dr. V. A. Kamath, Scientific Advisor; Attention: P. K. Patwardhan, Bhabha Atomic Research Centre, Trombay, Bombay, India

79. K. O. Laughon, AEC Site Kepresentative, ORNL

80. J. N. Rogers, Division 8321, Sandia Laboratories, P. O. Box 969, Livermore, California 94550 
81. Dr. Milton E. Rose, Mathematics and Computer Branch, Division of Research, U. S. Atomic Energy Commission, Washington, D. C. 20545

82-83. Technical Information Center (TIC)

84. Research and Technical Support Division, ORO 